José Manuel Lucía Megías

\title{
Elogio del texto digital 2.0 (¿el triunfo de la segunda textualidad?) In praise of digital text 2.0 (the triumph of the second textuality?)
}

Resumen: Todos (o casi todos) utilizamos las herramientas digitales en nuestras actividades científicas. Nos valemos de ellas para comunicarnos, para escribir nuestros trabajos, para acceder a fuentes documentales o para realizar análisis a partir de diferentes herramientas... Las bibliotecas digitales, los portales temáticos o las bases de datos se han convertido en una herramienta esencial en nuestras fuentes de información, de difusión de parte de nuestros resultados científicos, pero, ¿es suficiente?

Palabras clave: tecnología digital; bibliotecas digitales virtuales; bibliotecas digitales textuales; edición crítica digital.

Abstract: All (or almost all) of us use digital tools in our scholarly activities. We use them to communicate, to write studies, to access documentary sources, and to perform analyses using a variety of tools... Digital libraries, thematic portals and databases have become essential tools, used as sources of information and in the dissemination of our findings. But is it enough?

Keywords: Digital Technology; Virtual Digital Libraries; Textual Digital Libraries; Digital Critical Edition.

\section{Entre imágenes y metáforas: del objeto al uso}

La revista Time elige cada año a la "persona del año" entre aquellos que hayan tenido una mayor repercusión y presencia en los medios, entre aquellas personas

\footnotetext{
Nota: Este trabajo se inscribe en el marco del Proyecto I+D+i del MINECO DHuMAR Humanidades Digitales, Edad Media y Renacimiento. 1. Poesía 2. Traducción (FFI2013-44286-P) y del Proyecto Parnaseo (Servidor Web de Literatura Española) (FFI2014-51781-P), concedidos por el Ministerio de Economía y Competitividad.
}

José Manuel Lucía Megías, Universidad Complutense de Madrid

Ә Open Access. () 2019 José Manuel Lucía Megías, published by de Gruyter. (@)BY-Nc-ND This work is licensed under the Creative Commons Attribution-NonCommercial-NoDerivatives 4.0 License. https://doi.org/10.1515/9783110585421-008 
que permitan entender la singularidad de un determinado año, elección que realizan los editores y periodistas de la publicación (a la que se unen también los lectores, ahora cada vez más participativos). Así lo viene haciendo la publicación desde 1927, cuando se nombró "hombre del año" al aviador y aventurero Charles Lindbergh, que hizo el trayecto de Nueva York-París en solitario. Lindbergh se convirtió en leyenda con tan solo 25 años. Curiosidades de la vida, uno de los últimos "hombres del año" es Mark Zuckerbeg, co-fundador de Facebook, que tenía 26 años cuando fue nombrado en 2010. Y en medio encontramos a políticos como Roosevelt, Hitler, Stalin, Eisenhower, Truman, Churchill, Kennedy, Nixon, Willy Brandt, Reagan, Clinton, Bush, Obama o el propio Trump, sin olvidar a figuras como Gandhi, Juan XXIII, Martin Luther King o Juan Pablo II. Entre las mujeres, solo dos: Wallis Simpson (1936), la viuda que hizo abdicar al rey Eduardo VIII, e Isabel II en el año de ser coronada reina (1952). Además del citado Zuckerbeg, en las últimas convocatorias se han ido introduciendo algunas de las personas que han tenido algún protagonismo en la Sociedad de la Información y del Conocimiento que estamos creando con la tecnología informática: Andy Grobb (1997), por su vinculación a Intel, la empresa que ha llenado de microprocesadores el mundo, y Jeff Bezos (1999), fundador de Amazon.com, la mayor librería digital en la red, que también ha venido a difundir los libros (tanto analógicos como digitales) a lo largo y ancho de cualquier geografía. El mapa general de portadas de la revista Time en estos casi cien años de historia es un verdadero espejo de los grandes temas, de las preocupaciones de una sociedad (de la norteamericana, en particular; y de la occidental en general) durante este periodo. Y así, justo con nombres concretos, con personas relevantes, en ocasiones se ha prestado atención a colectivos: así en el año 1966 la persona del año fue la gente joven ("the shook up society, trusted no one over 30"), en 1998, la tierra que está en peligro, o el pasado año el movimiento Me too. En este interesante espejo de las portadas de Time, la informática aparece en dos ocasiones. Dos ocasiones que marcan también, en sus imágenes los grandes cambios que estamos viviendo en nuestros hábitos, en nuestros modos de trabajar, de comunicarnos, de relacionarnos, de comprender el mundo. En el año 1982, en vez de "persona del año" tendremos "machine of the year": el ordenador, tal y como aparece en la portada del primer número de 1983 (Figura 7.1).

Para representar al "ordenador” como concepto (la máquina del año) y no a un ordenador particular, la revista se valió de dos esculturas, en que se nos muestra a un hombre y a una mujer en espacios cotidianos antes que en un despacho o en una oficina; dos figuras que tienen delante estas nuevas herramientas, aunque no están interactuando con ellas. La mujer, incluso, sentada en un cómodo sillón, está con su taza de té (o de café) en una mano, y mirando al ordenador, a ese pequeño ordenador que hay sobre una mesilla, no sé si con recelo o 


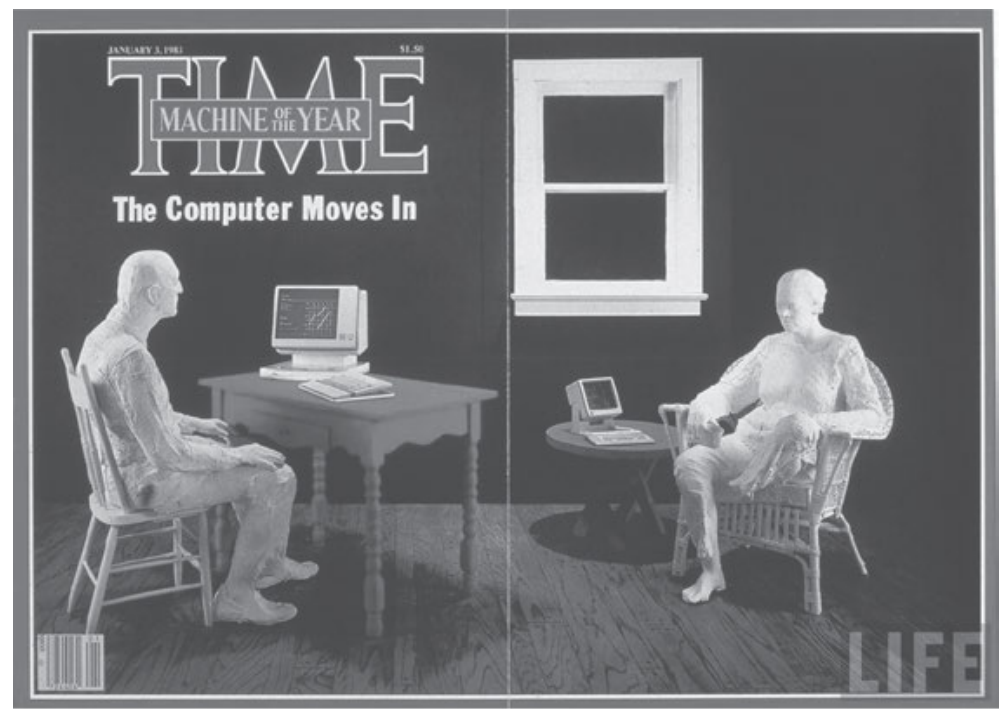

Figura 7.1: Portada de Time, enero de 1983.

un poco de hastío o de aburrimiento. Si nos fijamos un poco más en la imagen, veremos el espacio que ha conquistado el ordenador en el lejano ya 1982: el del trabajo. En las dos pantallas dibujadas aparecen gráficos y columnas de datos, nada de textos. El ordenador ha traspasado los límites de las oficinas y ha conseguido un tamaño que ha permitido su difusión. Es el principio de un cambio, un cambio que era en 1982 (como lo sigue siendo hoy en día) una revolución.

En 2006, "the person of the year" será "You"... y ante la cara de pregunta que se le pondría a los lectores del número de diciembre de Time, se indica a continuación de un "You" en negrita: "Yes, you. You control the Information Age. Welcome to your World" (Figura 7.2).

Y si en la portada de 1983, destacaban las dos esculturas estáticas ante la presencia de los ordenadores, casi 25 años después, que son los 25 del triunfo de la tecnología informática en nuestras vidas, en nuestra sociedad, el ordenador, una gran pantalla de ordenador (casi de un mac diríamos) es la que ocupa toda la imagen: una gran pantalla que es espejo de los propios usuarios de la red, de las nuevas herramientas y aplicaciones que se están poniendo a nuestra disposición, ya que desde el triunfo de la web 2.0, será el usuario no solo quien utilice esta nueva tecnología (una tecnología que ayuda en muchos de nuestros trabajos cotidianos), sino que también es creador de contenidos. Bienvenido a tu mundo, el que quieres consultar, el que quieres crear. En estas dos imágenes, en estas dos portadas de Time, en estos casi 25 años que las separan están fraguados algunos de los cambios fundamentales que estamos viviendo en la creación, conservación y difusión de la información (y con ella, del conocimiento): unos cambios 


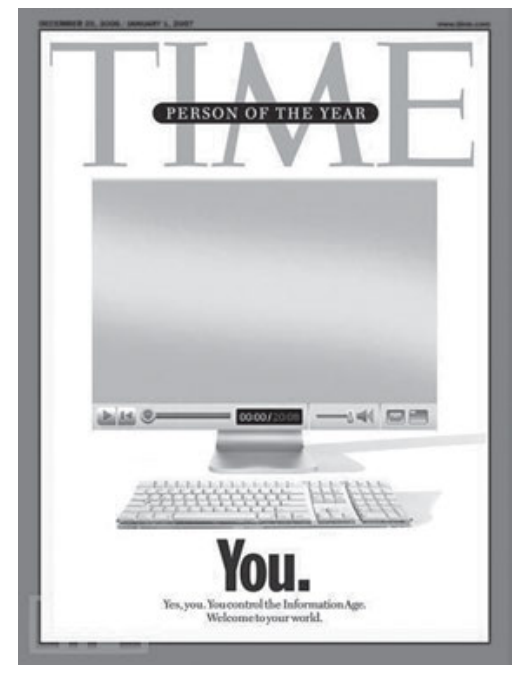

Figura 7.2: Portada de Time, diciembre de 2006.

que tienen que ver con aspectos económicos (la accesibilidad cada vez mayor a diferentes soportes y herramientas), con hábitos de trabajo y de vida, pero, sobre todo, con un cambio generacional. En 1982 se constató un hecho: la presencia del ordenador en la vida, más allá de esos enormes ordenadores de las grandes corporaciones administrativas, militares o empresariales. En el 2005, esta presencia ya se ha consolidado como habitual, propia de todos los ámbitos de la vida.

Se le atribuye al escritor, divulgador y creador de videojuegos Marc Prensky la metáfora de "nativos" e "inmigrantes" digitales para mostrar dos modelos de usuarios de las tecnologías informáticas: aquellos que han nacido, crecido y aprendido en un entorno digital (nativos) y aquellos otros que nos hemos tenido que adaptar a este nuevo entorno, pues nuestro nacimiento, crecimiento y aprendizaje proceden del ámbito analógico (y audiovisual) (inmigrantes). La metáfora nos retrotrae al 2001 y venía a explicar uno de los grandes problemas del sistema educativo de Estados Unidos de aquellos años: la imposibilidad que tenían los profesores de comunicarse con sus estudiantes. "El problema más importante que enfrenta hoy la educación" -decía Prensky- "es que nuestros profesores inmigrantes digitales, que hablan una lengua anticuada (la de la era pre-digital), están luchando para enseñar a una población de nativos digitales que habla una lengua completamente nueva".

La metáfora de "nativos" e "inmigrantes" digitales evoca territorios, espacios de poder, de categorías, y sigue la senda de los cantos de revolución democratizadora del saber gracias a la informática que había florecido en los años ochenta y noventa del siglo XX. En la metáfora de "nativos" e "inmigrantes" digitales pervive la visión de un territorio ideal, donde todo es posible para sus moradores, 
para sus nativos, y que, con mucho esfuerzo, podrá ser parcialmente disfrutado y apropiado por los inmigrantes, es decir, por aquellos que proceden de un territorio con menos oportunidades. A fin de cuentas, la emigración siempre es un desarraigo. Subyace en esta idea, que aceptamos casi sin darnos cuenta, una visión de territorios enfrentados, una supremacía de lo digital (presente y futuro) frente a lo analógico que se presenta, de este modo, como propio del pasado.

Frente a esta imagen de territorios, de espacios de poder y de incomunicación, en el 2010, el psicólogo alemán Peter Kruse, en una charla en YouTube, propuso una nueva metáfora, más acorde a los tiempos presentes, a los cambios que hemos vivido a partir del triunfo de las redes sociales y la web 2.0: la de "residentes" y "visitantes" digitales. Un "residente digital" vive en la red, accede y crea información en la red, se comunica en la red, deja memoria de su identidad en la red, con destrezas que, poco a poco, va adquiriendo porque el propio medio lo impone: inmediatez de publicación y difusión, multitarea (procesamiento en paralelo), o acceso en línea a miles de fuentes de información o conocimiento. Y al tiempo, los "residentes digitales" se comunican con sus amigos gracias a Twitter, Instragam o el WhatsApp; hacen visibles sus fotos en Picasa o sus vídeos en YouTube, actualizan sus muros en redes sociales personales (Facebook) o profesionales (LinkedIn), siguen la actualidad gracias a diversas Apps en su móvil o en su tablet, hablan con sus amigos por medio de Skype... sin olvidar cómo, día a día, son más los servicios y actividades (profesiones y personales) que realizan on-line. Al "visitante digital" no le son desconocidos muchos de estos servicios ni actitudes, pero los utiliza, si lo hace, de una manera esporádica, limitando su actividad en la red a la comunicación (correo electrónico) y a algunos servicios que le ofrecen ventajas económicas.

Uso frente a territorio. El universo digital no ha de entenderse tanto como un nuevo espacio, que, por solo el hecho de un dato cronológico (o geográfico) nos es propio o ajeno, sino como un proceso, una transformación, una apropiación que, todos juntos, vamos realizando. En la metáfora de "nativos" e "inmigrantes" se establece unas claras fronteras entre el mundo analógico y el digital, como si fueran dos realidades (casi) enfrentadas, dos "territorios" en conflicto, con pocas posibilidades de espacios de concordia y de estabilidad. Pero no hay "territorios" en el mundo digital. No hay hojas de ruta, pues (y este es uno de los grandes retos que tenemos por delante, uno de los más apasionantes), la tecnología digital no ha sido pensada para dar respuesta a un determinado reto tecnológico (como lo pudo ser el telégrafo, el teléfono, la radio, el cine o la televisión). Todo lo contrario. Año tras año, el espacio digital se va transformando, va abriendo nuevos (e insospechados) caminos. Algunos ya los hemos asimilado, o, poco a poco, lo vamos haciendo (la web 2.0 o las redes sociales)... y otros están todavía dando sus primeros pasos: de la tablet al smartphone, las pantallas táctiles, la conexión en línea, la multiplicidad de canales y de acceso a la información, etc. 
Este nuevo panorama, esta nueva perspectiva es la que me gustaría imaginar para las Humanidades en la era digital. No tanto un espacio de dos territorios casi en estado de guerra (o en una paz muy inestable o, en el mejor de los casos, en una mutua incomprensión e indeferencia), sino un espacio común, donde las Humanidades y la tecnología digital, es decir, las conocidas como Humanidades Digitales adquieran, por fin, el lugar que la nueva sociedad de la información y del conocimiento está demandando. Un espacio propio. Un espacio de diálogo. Un espacio que no esté marginado de los centros de investigación y docencia, de las Universidades. Este es uno de los grandes retos que las Humanidades tienen que afrontar en los próximos años. ${ }^{1}$

\title{
2 A modo de prolegómenos: veinte años no son nada
}

Hace 20 años, publiqué un artículo pionero sobre este tema (Lucía Megías 1998): "Editar en Internet”, en la revista Íncipit, que con tanta destreza y sabiduría dirigía el siempre añorado y llorado Germán Orduna. Un artículo que nació de un encargo de José Manuel Blecua, por aquel entonces asesor científico del Instituto Cervantes, que debía crear una revista electrónica (Preciosa, que nunca vio la luz), y una biblioteca virtual (que nunca pasó de ser un proyecto, pues tuvo que abortarse cuando apareció la "Biblioteca Virtual Miguel de Cervantes"). Si me he detenido en el detalle biográfico, es porque creo que es un ejemplo más, una historia muy similar a la de otros tantos filólogos que nos hemos acercado al mundo digital, cuando hace más de veinte años un hecho casual nos abrió los ojos a una nueva posibilidad, a un nuevo campo de estudio, en que seguimos aún hoy transitando:

\begin{abstract}
En estos momentos estamos viviendo, algunas a veces sin ser del todo conscientes, un proceso de revolución en los medios de transmisión del saber, como aquel que se consumó en la cultura occidental en la Alta Edad Media cuando se sustituyó el rollo, de origen romano, por el códice. El proceso actual, en cualquier caso, no tendrá las consecuencias de sustitución que se consumó en aquella época; el códice, en su formato manuscrito o impreso, pervivirá como medio de transmisión del saber y de la cultura, aunque ahora tenga que compartir su monopolio con nuevos formatos y canales; por su parte, la informática, con sus posibilidades inmensas de difusión en la Red, ha abierto interesantes novedades al concepto de "texto" y, en consecuencia, a nuestros modos de acercamiento y análisis del mismo (Lucía Megías 1998: 1-2).
\end{abstract}

1 En relación con el espíritu del presente capítulo, podrán leerse los trabajos: AAVV. (2015), Baraibar (2014), Borsari (2017), Lucía Megías (2010 y 2014), Rojas Castro (2013), Romero-Frías/ Del-Barrio-García (2014). 
Y la radiografía de algunas de las posibilidades editoriales digitales del momento (1998) y de las bibliotecas digitales (que por aquel entonces llamábamos telemáticas), no podía acabar de otro modo que con un canto de esperanza sobre los cambios que se iban a producir en la crítica textual en los siguientes años dadas las nuevas posibilidades de análisis y de difusión de nuestros textos:

Estamos llamados en los próximos años a descubrir las posibilidades que la Red ofrece a la crítica textual, más allá de la simple acumulación de textos en bibliotecas telemáticas y de la digitalización de las ediciones creadas y pensadas para su difusión en papel; en otras palabras, estamos obligados en los próximos años a aceptar el reto que este nuevo medio de difusión nos plantea; obligados a crear nuevos modelos de ediciones críticas en donde, al tiempo que se mantienen los principios teóricos en que se sustenta la ecdótica (y que este nuevo medio de difusión no modifica), se ofrezcan al lector una serie de materiales interrelacionados, que van desde la propia imagen de los testimonios conservados, las transcripciones de cada uno de ellos, como una peculiar manera de comunicar el texto crítico con su aparato tanto de variantes como lingüístico. La Red, de este modo, abre a la crítica textual un nuevo campo de investigación; un nuevo medio en el que poco a poco tendremos que ir creando nuestro propio lenguaje y nuestra propia técnica. La informática no es un sustituto de ninguna ciencia, sea esta la filología o sea esta la medicina, por poner solo dos ejemplos. La informática ha creado por una parte instrumentos y materiales en los que puede apoyarse el juicio del editor y por otra, gracias a Internet, un nuevo medio de transmisión con unas posibilidades que el tiempo y nuestros esfuerzos científicos pondrán en sus justos límites. Todo lo demás, por más que algunos sueñen con el mecanicismo como sinónimo de cientifismo, no es más que cantos de sirenas, cantos -en la mayoría de los casos desentonados- que no invalidan, en ningún caso, ninguno de los principios teóricos ni ninguno de los resultados prácticos de la ciencia de la crítica textual que llevamos más de un siglo perfeccionando (Lucía Megías 1998: 35-36).

¿Un canto de esperanza? ¿Cuántos de esos sueños y de esas esperanzas, veinte años después se han cumplido? ¿Hasta qué punto nuestros modos de analizar y estudiar los testimonios conservados, y de difundir nuestras lecturas críticas han estado a la altura de las expectativas con que muchos encarábamos el siglo XXI? ¿Se edita, se difunde de una manera diferente a nuestros clásicos en la actualidad que en los siglos precedentes cuando las posibilidades editoriales y tecnológicas actuales nada tienen que ver con las imposiciones analógicas del siglo XIX, el momento en que Lachmann y sus seguidores idearon un determinado modelo editorial de edición crítica?

Todo cambio en el paradigma de transmisión de los textos a lo largo de nuestra cultura occidental ha conllevado un cambio en la naturaleza de los mismos: de la oralidad a la escritura -la gran revolución textual triunfante en el siglo IV a. C.--, del paso del rollo al códice, con las transformaciones tecnológicas que se han vivido en los últimos siglos: tecnología manuscrita, tecnología de la imprenta manual, tecnología de la imprenta industrial, tecnología de la imprenta digital... todos ellos han 
supuesto un cambio esencial en la creación de textos -y de ahí- cambios también en las posibilidades de su edición y difusión. Y nuestra época no podía ser de otro modo. La literatura digital nada tiene que ver con la literatura analógica, y se están experimentando nuevos modelos textuales que nos sorprenderán en el futuro como ya lo están haciendo en el presente. Pero, ¿acaso estamos aprovechando estas innovaciones para crear nuevos modelos editoriales digitales más allá de la digitalización, la copia de los modelos antiguos? ¿Acaso hemos de conformarnos con meter en odres nuevos los vinos antiguos? ¿Es lo mismo difundir que editar, hacer accesibles los testimonios que comprender los textos que han transmitido?

El triunfo del códice - primero manuscrito y luego impreso- a partir del siglo VIII, supuso el triunfo de la página (o del bifolio) como unidad de lectura, de diseño de la mise-en-page, así como la posibilidad de una mayor densidad de información difundida en un mismo objeto -o un conjunto coherente de ellos-, lo que posibilitó el triunfo de las grandes compilaciones (históricas, épicas, religiosas, artúricas, etc. etc.). Y de ahí, al éxito del "libro unitario" manuscrito en el siglo XV, donde se establece una relación directa entre la "unidad textual” con la "unidad codicológica”, que se convertirá en una de las bases textuales del éxito de la industria de la imprenta a lo largo de los siglos XVI y XVII. Y de ahí a toda una serie de estrategias editoriales y comerciales donde el "destinatario" del objeto (del códice al libro impreso) deja de ser único para convertirse en múltiple, donde las estrategias se multiplican para hacer de la lectura un acto privado y de la compra de los libros un acontecimiento público. Este proceso llegará a su máxima expresión en el siglo XIX y principios del XX, cuando las librerías se conciben como "palacios de los libros", como la famosa librería de Espasa que se abrió en la reformada Gran Vía madrileña en 1905, que se promocionaba precisamente como "Palacio del libro". Años después, en una perspectiva más acorde a la decadencia de nuestros tiempos, pasó a llamarse como hoy la conocemos: "Casa del libro". 2

La tecnología digital, la que seguimos empeñados en denominar como “nuevas tecnologías”, aunque llevan con nosotros más de treinta años, y de nueva tiene bien poco, se ha instalado en nuestra vida científica. Y no solo. Lo digital, con su capacidad de reunir las diferentes morfologías de la información en unos mismos códigos matemáticos que pueden ser difundidos en variados soportes, se ha convertido en una herramienta esencial -necesaria e impuestaen nuestro día a día cotidiano y profesional.

2 No me detengo en más detalles, pues el lector interesado encontrará los datos desarrollados en Lucía Megías (2012 y 2015), con su pertinente bibliografía. 
Con la tecnología digital se han roto casi todas las fronteras de las dicotomías que habían fundamentado nuestra forma de ver y relacionarnos con el mundo a lo largo del siglo XX: fronteras entre lo personal y lo profesional, fronteras entre lo privado y lo público, fronteras entre lo común y lo prestigioso, fronteras entre lo científico y lo amateur, fronteras entre el conocimiento y la información... Y no siempre en este nuevo universo de transmisión de la información y del conocimiento, lo profesional, lo público, lo prestigioso y lo científico es lo que adquiere el mayor protagonismo.

¿La tecnología digital, con sus poderosas herramientas y sus nuevas posibilidades de crear estrategias nuevas de difusión de la información y del conocimiento, ha llegado para quedarse en nuestros estudios humanísticos, en la difusión de nuestros clásicos, en los cientos de textos que se escribieron y difundieron por medio de otras tecnologías, con otras modalidades de escritura y sus particulares soportes?

Todos (o casi todos) utilizamos las herramientas digitales en nuestras actividades científicas. Nos valemos de ellas para comunicarnos, para escribir nuestros trabajos, para acceder a fuentes documentales o para realizar análisis a partir de diferentes herramientas... Las bibliotecas digitales, los portales temáticos o las bases de datos se han convertido en una herramienta esencial en nuestras fuentes de información, de difusión de parte de nuestros resultados científicos, pero, ¿es suficiente? ¿Hemos ido más allá de la parte instrumental para llegar a plantearnos cómo podemos cambiar, cómo mejorar nuestros medios de edición textual, qué nuevas posibilidades nos ofrece la tecnología digital para hacer posible y real algunas de las máximas del neolachmannismo, tal y como lo soñó Contini, que hablaba de la edición crítica ideal como una "hipótesis de trabajo", como un "trabajo en el tiempo"?

El camino que se nos abrió hace más de veinte años fue grandioso. Pero aún no nos hemos atrevido a transitarlo. ¿O no hemos podido? Lo cierto es que hoy, como hace veinte años, muchas de las palabras que por aquel entonces escribimos podríamos hoy volver a hacerlo. ¿Cómo es posible que hayamos podido llegar a esta situación en que parece que el tiempo, en este mundo en continua transformación, se haya detenido?

\section{El principio del fin: el canto de sirena de Google Libros (2004)}

A la hora de analizar las diferentes bibliotecas digitales que comenzaron a proliferar en la Red a partir de los años noventa del siglo XX, y que solo unas pocas 
permanecen activas (o simplemente accesibles), hacía en aquel momento la distinción entre Bibliotecas Digitales Virtuales (aquellas que estaban más apegadas a la reproducción de los objetos que han permitido en el tiempo la difusión de los textos en el ámbito analógico: rollos, códices, libros impresos...), y las Bibliotecas Digitales Textuales (aquellas que difundían los textos, al margen de los testimonios que los habían difundido, siguiendo alguna de las diferentes metodologías ecdóticas que conocemos).

Las primeras estaban más vinculadas a los centros bibliográficos como Archivos y Bibliotecas, y las segundas eran objeto de proyectos de investigación universitarios o -en muchos casos- de proyectos personales de muy penosa continuidad. En ese segundo modelo, el de las Bibliotecas Digitales Textuales, la innovación no radicaba tanto en la metodología ecdótica seguida como experimentar nuevos modelos de edición que hacía posible el ámbito digital, más allá de la página -con sus aparatos de variantes o no a pie de página-, más allá de las limitaciones de trabajar en exclusiva con una morfología de la información -la textual-, más allá de las imposiciones editoriales del uso limitado de imágenes o de extensión textual, o del uso del color o el tamaño -o tipo- de las letrerías. Había llegado el momento de sacar el mayor provecho al lenguaje matemático que está detrás de esta nueva tecnología de la escritura, que solo mantiene en la superficie una similitud con las tecnologías del pasado. Lenguajes de marcado como el XML o el TEI, por solo citar algunos de los más usados -no sin ciertas críticas- parecían abrir nuevos campos cuya exploración nos permitió, por un tiempo, en soñar con nuevos modelos editoriales, con una nueva forma de dialogar con la crítica textual en nuestros días.

Solo dos ejemplos.

En el año 1999 nace RIALC, el Repertorio informatizzato dell'antica lirica catalana (http://www.rialc.unina.it/sommario.htm), dirigido por Costanzo di Girolamo. Es una de las primeras Bibliotecas Digitales Textuales, en las que se experimenta con situar, de una manera sencilla, tanto la información de los testimonios como de las variantes en la misma pantalla, aprovechando, de una manera muy sencilla las posibilidades de la horizontalidad de la nueva unidad de lectura, que pasa de la página a la pantalla (Figura 7.3).

Intratext (http://www.intratext.com) es una biblioteca digital en que las herramientas informáticas (concordancias, índices de frecuencia o alfabéticos, o las estadísticas lingüísticas) están insertadas en el texto mediante hipertextos, como se aprecia en el siguiente ejemplo de la primera de las rimas de Cecco Angiolieri (Figura 7.4).

Los ámbitos y finalidades de los dos modelos de bibliotecas digitales se habían establecido, de un modo claro, en muy poco tiempo, y constituían dos modelos que estaban llamados a entenderse y complementarse, por más que 

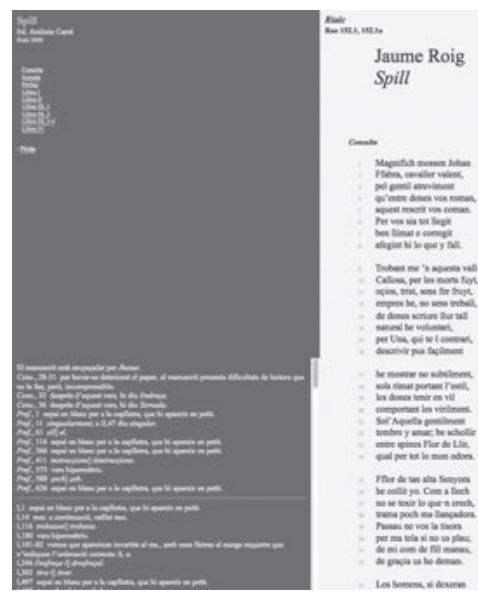

Figura 7.3: RIALC: Spill. Ed. Antònia Carré (2000).

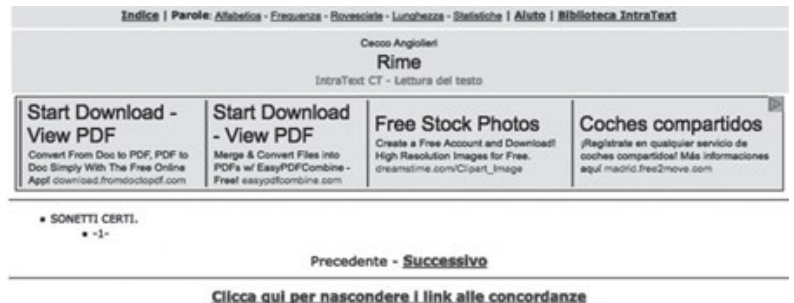

SONETTI CERTI.

-1-

- Accorri accorri accomi, pom, a la strada!

- Che ha', $\mathrm{fl}^{\prime}$ de la putta? - $\mathrm{r}$ son rubate.

- Chi t'ha rubato? - Una che par che rada

come nasoio, si m'ha netto lasciate.

- Or come non le davi de la spada?

-I' dare' anz'a me. - Or se' 'mpazzato?

- Non se che 7 dill, cosi mi par che yada.

-Or t'avess' ella ciece, sciagurate!

- E vedi che ne pare a que' che 'I sanno?

- Dil quel che tu mi rubi. - Or ya con Die.

ma anda pian, ch'i' yo' planger lo danne.

Figura 7.4: INTRATEXT: Cecco Angiolieri, Sonetto 1. 
los responsables de los centros bibliotecarios o archivísticos por aquellos años entendían que los objetos digitalizados en sus centros con fondos públicos les pertenecían y no se podían exportar a otras plataformas. Me callo las diferentes aventuras y anécdotas que todos los medievalistas que por aquel entonces -desde hace más de veinte años- trabajábamos en este campo tuvimos que sufrir. Nada que ver con la época actual.

Pero todo cambió en el año 2004, cuando Google anunció su gran proyecto textual: Google Books, que tenía la finalidad no solo de pasar todo lo que estaba off del mundo digital a on, digitalizando los fondos bibliográficos analógicos de las mayores bibliotecas de todo el mundo -comenzando por las universitarias de Estados Unidos y de Gran Bretaña-, sino que pretendía revolucionar el mundo editorial mundial, al ofrecer tanto las obras libres de derechos como las actuales -gracias a acuerdos con las editoriales- en formatos digitales. De este modo, Google Libros estaba llamado no solo a convertirse en el gran digitalizador de las obras del pasado sino en la gran librería de las del presente, siendo el vehículo de comunicación directo entre las editoriales y los lectores, dejando obsoletos los "palacios de libros", en un evidente error de perspectiva que sí que supo -y sabe- aprovechar Amazon, que se ha convertido, al saber mantener la estructura de las librerías (y tiendas en general) con sus productos físicos y la posibilidad de añadir recursos y herramientas digitales, en el mayor suministrador de contenidos (que no solo de información) de todo el planeta. Ya tendremos ocasión de volver sobre el tema en las conclusiones.

Con la perspectiva de trece años, el proyecto Google Libros tal y como se ideó ha sido un fracaso, aunque sigue siendo una fuente única para seguir haciendo del Buscador de Google el más universal y utilizado en todo el mundo, por encima de cualquiera de sus competidores. Pero este fracaso en el tiempo ha supuesto un cambio total de perspectiva en el desarrollo y la innovación de las bibliotecas digitales, en paralelo a los enormes cambios que hemos vivido desde el año 2004 hasta nuestros días: el triunfo de la Web 2.0 (2005) y la aparición de las tabletas, con el I-pad de Apple a la cabeza (2010). Dos cambios de muchos de los que se han completado y otros tantos que esperan para lanzarse a un mercado adecuado y una situación económica participativa.

La amenaza de Google Books, y como tal fue sentida por muchas bibliotecas nacionales (con la de Francia a la cabeza, y su biblioteca digital Gallica, que se convirtió en modelo y campo de experimentación), y por la política digital europea, ha conllevado que la mayoría de los millonarios recursos que se han puesto a disposición de los investigadores para plantear una alternativa a la del gigante Google se hayan utilizado para la digitalización de fondos y el apoyo a la creación de Bibliotecas Digitales Virtuales, dejando en un segundo plano las Bibliotecas Digitales Textuales. En una primera fase, se hizo un gran esfuerzo -del que hoy 
todos nos beneficiamos- para ofrecer digitalizaciones de calidad de los tesoros bibliográficos conservados en las bibliotecas y archivos, pero, en los últimos años, lo que se ha hecho es un gran esfuerzo para experimentar en la presentación de los materiales y en las herramientas de búsqueda, para hacer accesibles los materiales a las personas interesadas en su consulta.

La Biblioteca Digital Mundial es un buen ejemplo de este recorrido.

Nació como idea en el año 2005, en un discurso del bibliotecario del Congreso de EE.UU. James H. Billington ante la UNESCO. La primera versión se puso en la red en abril de 2009, con material procedente de todos los miembros de la UNESCO (Figura 7.5).

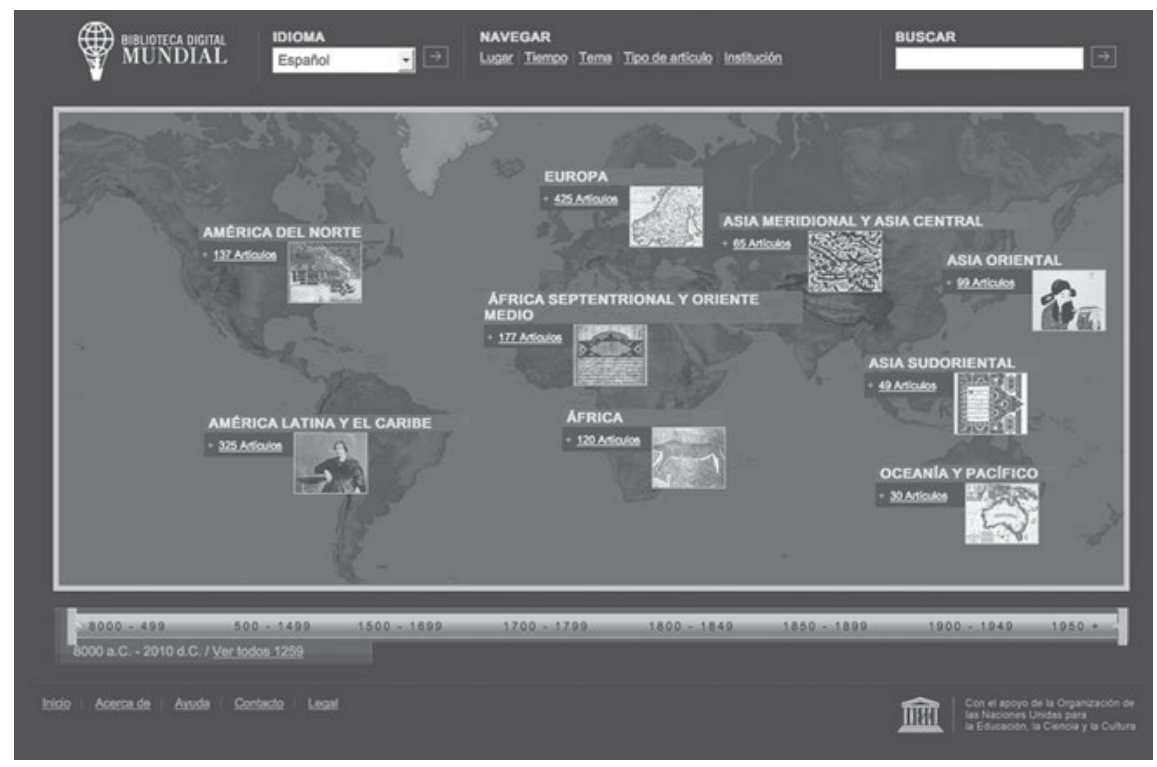

Figura 7.5: Biblioteca Digital Mundial: año 2010.

En estos años, la Biblioteca Digital Mundial, como tantas otras Bibliotecas Digitales Virtuales -como la propia Biblioteca Digital Hispánica de la Biblioteca Nacional de España-, no ha dejado de incluir materiales digitales nuevos, pero, sobre todo, no ha dejado de experimentar en la presentación de los materiales, en las diferentes opciones de búsqueda y de difusión de los resultados, siendo la Web 2.0 una de las herramientas imprescindibles en este tipo de proyectos científicos.

Un aspecto que hace particular la Biblioteca Digital Mundial es entender cada objeto digital como un "artículo", en que se enriquece el objeto digitalizado con información autorizada y etiquetas que lo vinculan a otros objetos/artículos del 
mismo portal, gracias a compartir género, época, personajes, etc. Se trata de poner las bases de una "enciclopedia" del saber a partir de los objetos creados para la difusión de la información y del conocimiento a lo largo de los siglos (Figuras 7.6 y 7.7).
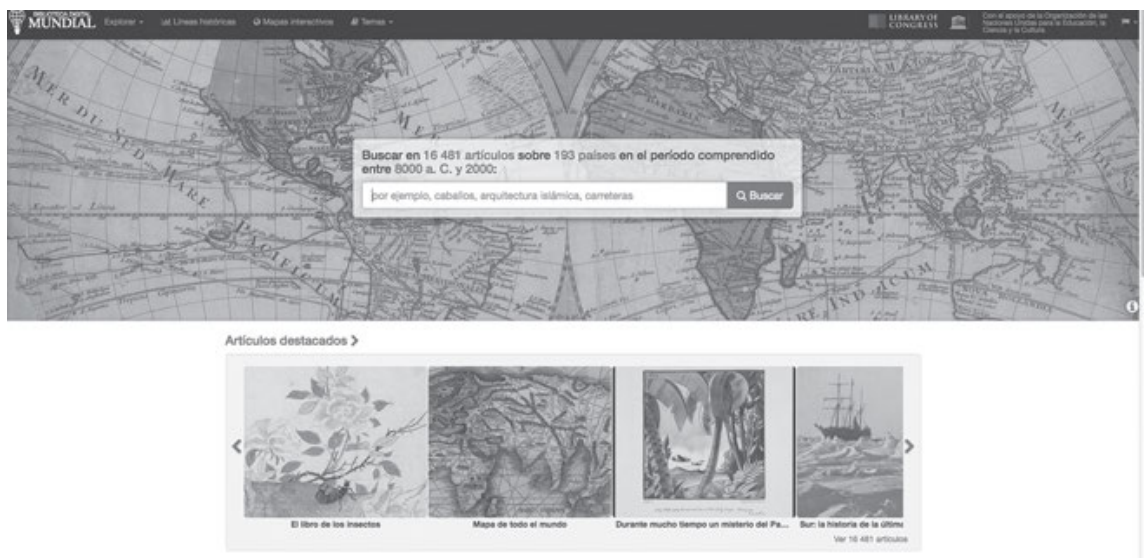

Inatuviones destacadas >

Figura 7.6: Imagen actual de la Biblioteca Digital Mundial.

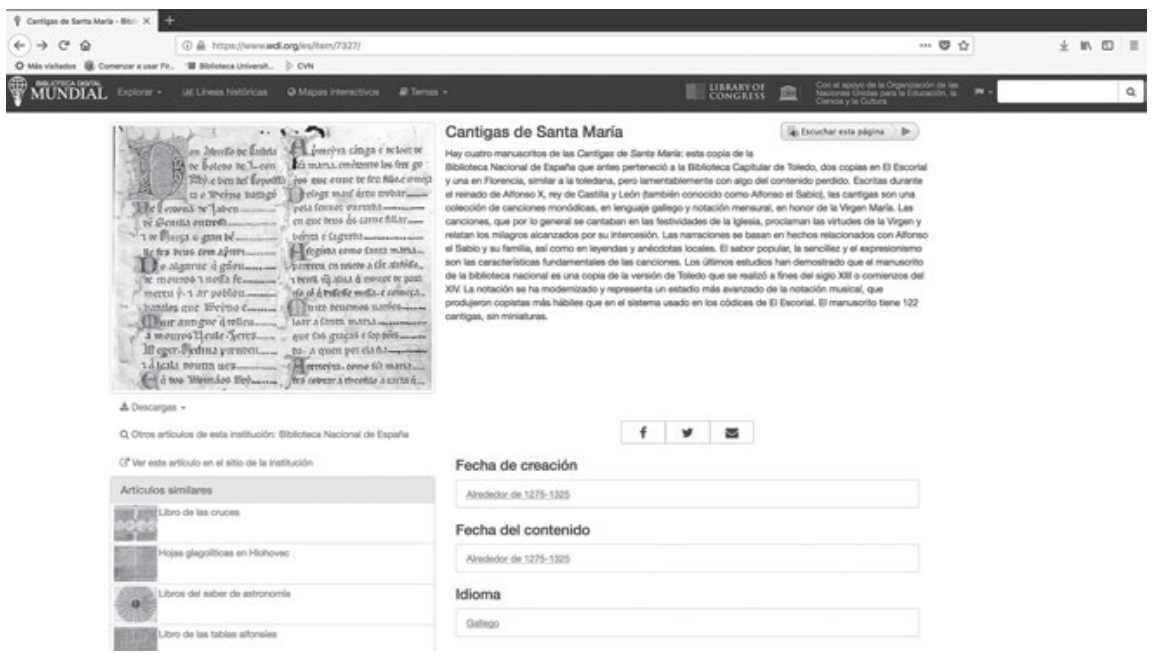

Figura 7.7: Imagen del artículo “Cantigas de Santa María” de la Biblioteca Digital Mundial.

Un esfuerzo similar de adaptación a los nuevos tiempos, de evolución de una Biblioteca Digital, que sigue apostando por lo textual, aunque experimentando más con las presentaciones y herramientas de búsqueda y en la 
necesidad de adaptación tecnológica a los lenguajes más estándares en la Red, lo ha propiciado la Biblioteca Virtual Miguel de Cervantes, desde su nacimiento en 1999 (Figura 7.8).
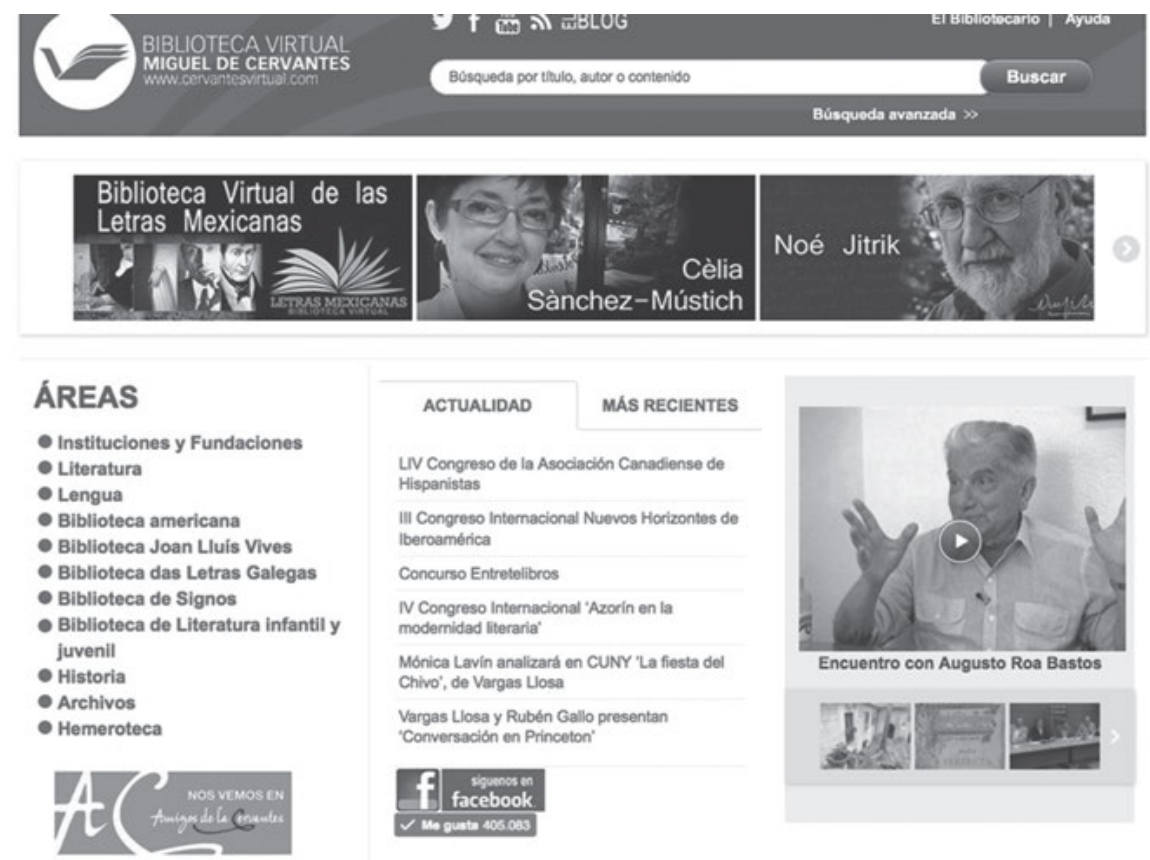

VATREA I Impact LIOSA succeed
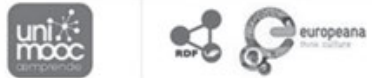

Figura 7.8: Biblioteca Virtual Miguel de Cervantes.

\section{Futuro inmediato: de las fontes criticae a la dispositio textus}

La gran revolución tecnológica -y vital- que hemos vivido en los últimos treinta años comenzó con el paso de Internet a la Web, es decir, el paso de interconectar los ordenadores gracias a una serie de protocolos internacionales estandarizados, a hacer posible que se pudiera interconectar la información que estos ordenadores albergaban. De la máquina al contenido. Nuestra propia evolución 
humanística tiene que ir por el mismo camino: del objeto digitalizado al texto que difunde, a la información que transmite.

Es mucho lo que hemos avanzado tecnológicamente en los últimos años -y mucho más lo que seguiremos avanzando en los próximos años-; es muy importante la experiencia que hemos acumulado en los últimos veinte años para no repetir los mismos errores ni lamentaciones en las mismas carencias; y sobre todo, ahora tenemos a nuestra disposición no solo la metodología ecdótica, sino que, ahora, por primera vez, se nos pone a nuestra disposición el material digitalizado de buena parte de los testimonios conservados de nuestras obras medievales, base esencial para poder plantear las "hipótesis de trabajo" de nuestro texto crítico. Nunca hemos contado con herramientas más perfeccionadas para completar la primera fase de toda edición crítica: las fontes criticae, así como se perfeccionan herramientas digitales que nos ayudarán en la collatio, tanto externa como interna de nuestros testimonios.

Pero además de las herramientas que permiten seguir profundizando en hacer accesibles muchos de estos materiales, como son las bases de datos textuales, bibliográficas o iconográficas o las bibliotecas digitales virtuales, se hace necesario volver la vista al ámbito de la experimentación de nuevos modelos editoriales de nuestras obras medievales, que tendrán que concretarse en ediciones digitales críticas, recogidas en novedosas Bibliotecas Digitales Textuales.

Tres ámbitos de estudio están demandando en la actualidad una respuesta por parte de la comunidad científica, y solo desde los centros universitarios, con todo el apoyo de bibliotecas y archivos, puede llevarse a cabo:

1. Por un lado, la creación de plataformas de edición estandarizadas donde se pueda, de una manera sencilla y normalizada -siguiendo el modelo de la difusión de los blogs y de sus plantillas de edición-, tanto introducir nuevos textos editados como establecer relaciones entre estos y los testimonios digitalizados, las transcripciones y presentaciones críticas, la vario lectio, que documentan y, por supuesto, nuestra hipótesis de trabajo del texto crítico.

2. Por otro lado, se hace necesario crear estándares y modelos necesarios para convertir en una realidad uno de los principios de la crítica textual neolachmanniana: la edición crítica como una "edición en el tiempo", para así poder conocer e implicar dentro de nuestra edición no solo los materiales pertinentes de nuestro texto crítico (testimonios, varia lectio, aparatos de variantes...), sino también las conclusiones a las que han llegado los lectores y editores del pasado y aquellas otras que puedan formular los lectores y editores del futuro, así como nuestros propios cambios y replanteamientos críticos. Es importante que en la edición crítica digital se deje huella del proceso filológico para su configuración, pero también del proceso de su lectura y recepción. 
3. Y por último, por solo poner en evidencia un campo nuevo, se hace necesario establecer los protocolos necesarios para que los distintos tipos de lectores puedan acceder a la información textual según sus intereses particulares en cada momento, implicando en la edición crítica digital no solo los materiales que han llevado al editor a su hipótesis de trabajo, su propio texto crítico, con todos sus aparatos de variantes y de análisis filológico, sino todas las herramientas digitales para sacarle el máximo partido a cada edición, a ampliar las fuentes de información para futuras investigaciones. Una edición que, de este modo, pasa de ser un producto único para formar parte de una Biblioteca Digital Textual, cuya naturaleza vaya más allá de la simple acumulación de objetos (analógicos o digitales) en estanterías, índices, para convertirse en una herramienta eficaz para encontrar novedosas informaciones que nos lleven a seguir avanzando en el conocimiento.

\section{Elogio del texto digital 2.0}

Los procesos de cambios tecnológicos que afectan a las unidades textuales $-\mathrm{y}$ no solo- que hemos vivido en los últimos miles de años han repetido un mismo esquema, con unas fases fácilmente reconocibles:

1. Con la aparición de una nueva tecnología que viene a debilitar el monopolio de una tecnología anterior triunfante, se van a dar dos posiciones enfrentadas:

a. Los defensores de la nueva tecnología, en que cifran la solución de todos los problemas de nuestra sociedad.

b. Los detractores de la nueva tecnología, que equiparan con el principio del fin de todos los valores de nuestra sociedad.

2. Después de una fase de enfrentamiento y de posturas irreconciliables (¿Esto matará aquello? era el título de un congreso sobre el libro electrónico a principios del siglo XXI), se produce una fase de convivencia, en que las dos tecnologías se reparten los espacios de poder y de difusión, creándose productos híbridos, que no terminan de abandonar los modelos anteriores ni tampoco le sacan todo el partido a las nuevas posibilidades de la nueva tecnología.

3. Y por último, en el momento en que se desarrollan nuevos modelos atendiendo a las nuevas posibilidades de la tecnología y no a mantener modelos híbridos ya superados, se produce el triunfo del nuevo modelo, y el antiguo ha de buscar espacios de supervivencia, que, en la mayoría de los casos, son marginales y muy limitados en el tiempo. 
Son muchos los ejemplos textuales que podríamos aquí mostrar para ejemplificar las diferentes fases del cambio tecnológico, como el propio del rollo al códice, o el de la imprenta en el siglo XVI, mucho más conocido y estudiado. Pero, quiero detenerme en un ejemplo más actual, cuyos resultados todavía no están claros, pues estamos en ese momento fascinante en que lo antiguo ya no vale, lo nuevo está experimentando y todavía no sabemos dónde se establecerán los estándares y modelos del futuro.

El periodismo ha sido, sin duda, la gran revolución desde el siglo XIX hasta nuestros días, un proceso que ha venido de la mano de algunas de las posibilidades tecnológicas en los últimos siglos, desde la imprenta industrial -cuya base económica procederá precisamente de los monopolios periodísticos de Europa y de Estados Unidos-, hasta la fotografía o las agencias de noticias. ¿Cuál ha sido la respuesta de la prensa, de las grandes corporaciones de la comunicación ante el reto de la tecnología digital? ¿Cuál es el modelo actual y cuál el modelo que podemos vislumbrar para el futuro?

Hemos pasado de la negación a las versiones digitales de los periódicos, que comenzaron de pago y solo de una manera marginal, para convertirse ahora en una parte esencial de las redacciones, en ocasiones tan o más cuidadas que las versiones en papel, dado que el medio digital ofrece una ventaja esencial para el periodismo: la capacidad de una actualización inmediata. ¿Cuál es la situación actual, al menos en España? No es posible dar cuenta de la realidad periodística solo teniendo en cuenta los periódicos de difusión tradicional en papel, sino que es necesario sumar cabeceras digitales, solo digitales.

Pero además del medio, en estos últimos años se ha ido modificando un elemento esencial del periodismo, con el triunfo de los blogs: la pérdida del monopolio de la información, la incapacidad del control de los contenidos. En Estados Unidos, los blogs comienzan a popularizarse en el año 2001, pero será hasta el 2006 o 2007 cuando sean una realidad en España y en el resto de Europa. El blog constituyó el primer elemento de la incorporación de la web 2.0 en el universo periodístico que, por principio y por final empresarial, presenta una estructura jerárquica que nada tiene que ver con su espíritu. La participación de los lectores -o de los oyentes en la radio o de los espectadores en la televisión-comenzó a ser cada vez más habitual. No era nada nuevo, pero lo novedoso sí que era su presencia cada vez más habitual y abundante. No hay periódico, no hay programa de radio general, no hay programa de televisión generalista que no tenga su espacio abierto a los comentarios, a la participación. ¿Es este medio híbrido, de prensa digital en una estructura de poder analógica, la que va a preservar? ¿No estamos ante los últimos estertores de un modelo periodístico que tuvo su sentido en el siglo XIX y que se mantuvo en el XX, pero que está muy alejado de lo que la sociedad -y la política y la economía- está demandando? ¿Cuántos de los blogs 
de los más famosos periodistas se mantienen y hay una verdadera demanda de escuchar sus opiniones, ya sea en formato escrito o en vídeos de YouTube? ¿Qué porcentaje de la sociedad está ajena a estos modelos de acceso a la información y del conocimiento, y se acercan a otros modelos, como son los youtubers, cuya permanencia solo el tiempo nos lo dirá?

Las versiones digitales de los periódicos -con sus redacciones, líneas editoriales, compromisos económicos y empresariales-, aprovechan un elemento esencial de nuestra sociedad: la actualidad e inmediatez de la noticia. Pero ¿es este medio el más apropiado para dar respuesta a las nuevas demandas de una sociedad que necesita respuesta ya a los conflictos o los problemas que le interesan en cada momento, una sociedad que premia antes la inmediatez que el análisis reposado? ¿Será la prensa digital la respuesta del futuro a las nuevas demandas de nuestra sociedad? Sin duda que no. Desde hace ya unos años hay otro medio más inmediato, más abierto, menos jerarquizado que va ocupando esa posición: Twitter. Con sus 140 caracteres -ahora unos más- y, sobre todo, por sus hashtags, sus etiquetas, se ha convertido en un medio único, nuevo de generación de noticias, de información, de opinión. El hecho de que Donald Trump, acosado por la prensa tradicional, lo esté utilizando como su medio habitual de comunicación, más allá de las ruedas de prensa, de los comunicados o de las conversaciones personales con los periodistas y los medios, está trastocando todo el modelo textual periodístico hasta ahora conocido. ¿Cómo será el texto de un periódico con redes sociales como twitter en el futuro? Ni idea... como tampoco podrían imaginar cómo terminaría siendo la página de un periódico actual los lectores de las cabeceras del siglo XIX, donde la lectura secuencial por columnas era el único elemento textual que entendían y que demandaban.

$Y$ con estos detalles del mundo actual, un mundo digital a fin de cuentas, con una mirada medieval, quisiera acabar. Y lo quisiera hacer con un elogio del texto digital, a este particular texto digital actual, al que he puesto el apellido de 2.0, aunque ya seguramente tendríamos que hablar de otras versiones mucho más actuales.

Mientras que no seamos conscientes que el texto digital es algo más que la digitalización de los textos del pasado -ya sean en los códices o libros que lo han transmitido, ya sea en sus formas textuales basadas en las imposiciones de una página, limitación de la tecnología del códice-, y que un texto digital posee una doble naturaleza: por una lado lingüística -basada en la tecnología de la escritura que se impone en nuestra sociedad occidental a partir del siglo IV a.C.--, y por otra matemática, que es la que nos permite adentrarnos en nuevos modelos textuales -y de ahí, a nuevos modelos de edición y nuevos modelos de bibliotecas-, seguiremos viviendo en la época del incunable del texto digital, en ese momento de transición en que, aprovechando algunos elementos propios de la tecnología digital, seguimos todavía apegados a los modelos antiguos, a sus limitaciones tecnológicas. 
Los programas de marcado y etiquetado para la edición de textos, en especial TEI/XML, están muy bien para dejar constancia de las características físicas de los textos en su difusión mediante manuscritos o mediante libros impresos, saber si estamos ante una letra inicial o una frase que pertenece a un epígrafe, a un colofón o al cuerpo del texto. Pero en este camino seguiremos todavía transitando sendas del pasado que no creo que nos lleven a nuevos modelos editoriales o científicos, que son los que están demandando los nuevos tiempos.

Volviendo a las primeras imágenes, a las metáforas con que comenzaba, el gran motor del cambio en los últimos años en el uso y desarrollo de la tecnología digital no ha sido tanto la estructura como el uso. Han sido los usuarios que han demandado nuevos modelos de relación o de intercambio los que han motivado los cambios que han sido revolucionarios en el mundo digital, sobre todo después del triunfo de la web 2.0 hacia 2006.

El trabajo realizado en estos últimos años para editar los textos medievales ha sido enorme y, en muchas ocasiones, exitoso. Sin duda, debemos sentirnos muy orgullosos del camino transitado. Pero hoy, como hace veinte años, tenemos que ser optimistas y mirar con esperanza el futuro, pero solo si somos capaces de superar esta primera fase del incunable del texto digital, donde nos hemos empeñado en no cruzar el abismo que va de las estructuras analógicas a las digitales. Ahora ha llegado el momento de dar el salto, ha llegado el momento de escuchar y de apoyar a los residentes digitales para que nos conduzcan a una nueva edad de oro de las ediciones críticas digitales de nuestros clásicos. Una nueva era en que superemos los miedos y limitaciones del pasado y nos adentremos en las posibilidades del futuro, que, pasan, a mi modo de ver por la creación de estándares de uso fácil, casi intuitivo, para la edición y para la conservación de nuestros textos, más allá de las digitalizaciones, más allá de la copia de modelos tradicionales en formatos novedosos. Ha llegado el momento de ser valientes y de soñar con nuevos modelos editoriales para la difusión y la conservación de nuestros clásicos. La metodología la conservamos, el conocimiento lo tenemos, la necesidad se impone y las posibilidades tecnológicas cada vez son más accesibles. El texto digital está ahí, a nuestras puertas: solo tenemos que ser valientes y darle la bienvenida, con todas sus consecuencias.

\section{Referencias bibliográficas}

AAVV. (2015): La realidad de las Humanidades Digitales en España y América Latina. Monográfico de ArtyHum, Revista de Artes y Humanidades, no 1. https://www.artyhum. com/descargas/monograficos/MONOGR\%c3\%81FICO\%20HD.pdf 
Baraibar, Álvaro (2014): “Las Humanidades Digitales desde sus centros y periferias”. En: Janus: estudios sobre el Siglo de Oro, №. Extra 2. Anexo 2 [Ejemplar dedicado a: Humanidades Digitales: una aproximación transdisciplinar, Álvaro Baraibar Etxeberria (ed. lit.)], pp. 7-15.

Borsari, Elisa (2017): “Los albores de las Humanidades Digitales dentro del espacio de la Asociación Hispánica de Literatura Medieval y su evolución”. En: Miranda, José Carlos Ribeiro (coord.): En Doiro Ant'o porto e Gaia. Estudos de Literatura Medieval Ibérica. Porto: Estrátegias Creativas, pp. 237-253.

Lucía Megías, José Manuel (1998): “Editar en Internet (che quanto piace il mondo è breve sogno)”. En: Incipit, XVIII, pp. 1-40.

Lucía Megías, José Manuel (2010): “Los nuevos filólogos del siglo XXI: la literatura medieval hispánica en la Red”. En: Fradejas Rueda, José Manuel/Dietrick, Deborah Anne/Díez Garretas, María Jesús/Martín Sanz, Demetrio (eds.): Actas del XIII Congreso Internacional de la Asociación Hispánica de Literatura Medieval (Valladolid, 15 al 19 de septiembre 2009). Valladolid: Universidad/Ayuntamiento de Madrid, tomo II, pp. 1233-1254. [En línea, http://www.ahlm.es/IndicesActas/ActasPdf/Actas12.2/ LUCIA_MEGIAS_JOSE-MANUEL.pdf].

Lucía Megías, José Manuel (2012): Elogio del texto digital. Madrid: Fórcola.

Lucía Megías, José Manuel (2014): “Las Humanidades Digitales: una oportunidad para los hispanistas del siglo XXI”. En: Baraibar Etxeberria, Álvaro (ed.): Humanidades Digitales: una aproximación transdisciplinar. Janus. Anexo 2. pp. 99-116. [En línea, http://www. janusdigital.es/anexos/contribucion.htm?id=49, consultadoen09/10/2017].

Lucía Megías, José Manuel (2015): “Las humanidades digitales en el espejo de la literatura medieval: del códice al Epub”. En: Alvar Ezquerra, Carlos (coord.): Estudios de literatura medieval en la Península Ibérica. San Millán de la Cogolla: Cilengua, pp. 95-122.

Rojas Castro, Antonio (2013): “El mapa y el territorio. Una aproximación histórico-bibliográfica a la emergencia de las Humanidades Digitales en España”. En: Caracteres, 2, pp. 10-53.

Romero-Frías, Esteban/Del-Barrio-García, Salvador (2014): “Una visión de las humanidades digitales a través de sus centros". En: El profesional de la información, 23.5 (septiembreoctubre), pp. 485-492. [En línea, http://www.elprofesionaldelainformacion.com/ contenidos/2014/sept/05.html]. 